\title{
FRAGILITY OF EXISTING ITALIAN BRIDGES TO TRAFFIC LOADS
}

\author{
G. Miluccio ${ }^{1}$, D. Losanno ${ }^{1}$, F. Parisi ${ }^{1}$, and E. Cosenza ${ }^{1}$ \\ ${ }^{1}$ Department of Structures for Engineering and Architecture, University of Naples Federico II \\ Via Claudio 21, 80125 Naples, Italy \\ e-mails: giacomo.miluccio@unina.it, daniele.losanno@unina.it, fulvio.parisi@unina.it, \\ cosenza@unina.it
}

\begin{abstract}
Fragility curves are a well-established tool to define probabilistically the vulnerability of an asset to a prescribed hazard. The majority of previous studies have investigated the seismic fragility of structures and infrastructures. Nonetheless, recent disasters have highlighted the need to assess the vulnerability of aging bridges to gravity loads. Based on existing data from the literature and novel data from some real case studies, the present work presents analytical fragility curves of Italian bridges to traffic loads. The class of simply supported, beamtype, prestressed concrete bridges constructed between 1960 and 1980 was considered, given that those structures are the most recurrent type of existing Italian bridges. Then, a fragility analysis was performed through a fully automated procedure implemented in MATLAB. Geometric, material and load parameters were defined as random variables considering their probability distribution and correlation through either univariate or multivariate models. Structural fragility was evaluated with respect to the limit state of collapse. The output of this study can be of interest to engineers and decisions makers who must manage existing bridges, considering their probability of collapse under traffic loads and eventually limiting their use before structural retrofitting.
\end{abstract}

Keywords: Prestressed concrete bridges; traffic loads; fragility; collapse limit state. 


\section{INTRODUCTION}

Structural safety of existing bridges is involving the worldwide engineering community during the last years due to recent casualties. In the aftermath of the Polcevera bridge collapse in Genoa in 2018 [1], an increasing attention has been paid towards safety evaluation and monitoring of existing bridges with a service life approaching to or even exceeding 50 years. This trend also led to new Italian guidelines for classification, safety checks and monitoring of existing bridges issued by the High Council of Public Works in April 2020 [2]-[4]. During the last years, overloads, collisions, flood and environmental degradation caused more than $80 \%$ of the total collapse cases [5]-[7][7]. Furthermore, the structural assessment and retrofitting of existing bridges is urgently needed also because of aging and material deterioration, lacking or ineffective maintenance, and climate change in multi-hazard environments involving both human-related and natural events.

The study of existing bridges should take into account the following points:

(i) Traffic load conditions have been changing over time, i.e. different traffic loads were prescribed during original design in comparison with current code provisions.

(ii) Materials adopted in the past are not compliant with modern building codes and may be affected by significant variability and deterioration.

In this study, the structural fragility of a class of existing Italian bridges subjected to traffic loads is studied according to code-conforming capacity models and analysis procedures [8][8]. The most important properties of the bridge decks were probabilistically modelled based on available data, randomly sampled via Monte Carlo technique, and propagated through structural analysis. Fragility analysis was fully implemented in MATLAB software [9][9], providing the conditional probability of collapse given the intensity level of code-conforming traffic loads.

\section{METHODOLOGY}

This study aims to define the vulnerability of existing Italian bridges subjected to codecompliant traffic loads. Previous studies investigated the seismic fragility of bridges, but recent disasters highlighted the need for a comprehensive investigation on their vulnerability to human-induced loads. A class of simply supported, beam-type, prestressed concrete (PC) bridges was considered, since they represent more than $90 \%$ of the total bridge population in Italy [10][10]. Previous studies [10][10]-[12][12] also reported that the time frame 19601980 is the period when the highest number of bridges were built due to Italian economic growth and infrastructure development. In those decades, a relevant part of the Italian road network was built. Based on available data collected by the authors on real case-study bridges, the period 1970-1980 was chosen in order to carry out the fragility analysis of existing bridges. Figure 1 outlines the methodology used in this study to assess the vulnerability of existing bridges to traffic loads, the distribution and design values of which was defined according to the Italian building code [8][8].

The material, geometric and load uncertainty models were defined in order to generate a set of case studies through a Monte Carlo simulation. Demand and capacity analysis were carried out and the performance level of each model was calculated. The counted fragility was evaluated applying a frequentist approach. A lognormal distribution function was then fitted to fragility points in order to obtain fragility curves. 


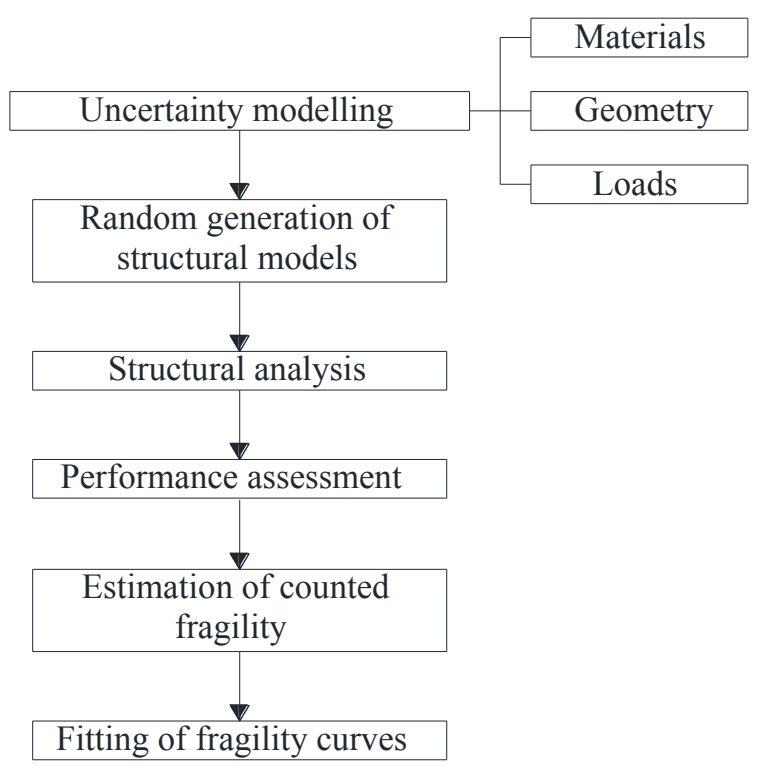

Figure 1: Flowchart of fragility analysis.

\section{UNCERTAINTY MODELLING}

Random variables (RVs) included both geometric and material properties. Based on [10][10] and some real case-studies, a subset of RVs were modelled through probability distributions, whereas other RVs were assumed to be statistically dependent upon the former RVs according to regression models. To that aim, the authors examined:

- geometric properties of 14 bridges built in the period 1960 to 1980;

- experimental data on mechanical properties of concrete (100 data), mild reinforcing steel (65 data), and prestressing steel (21 data) of bridges dating back to the period 1970-1980.

Case-study bridges have different locations in Italy and were built by different construction companies to be representative of the selected class of bridges. In the following sections, probability distributions and regression models are described.

\subsection{Material properties}

The database of material properties was based on laboratory test results of real case-studies collected by the authors. Figure 2 a shows three alternative probability distributions fitted to experimental data to model the uncertainty in concrete compressive strength $f_{c}$, namely normal, lognormal and Weibull distribution. Based on best fitting, the lognormal distribution with mean value of $38.5 \mathrm{MPa}$ and coefficient of variation $(\mathrm{CoV})$ of $11.4 \%$ was assumed.

The same procedure was applied to derive a probability distribution for the yield strength $f_{y}$ of mild steel (Figure 2b). Best fitting produced a lognormal distribution with a mean value and $\mathrm{CoV}$ equal to $436 \mathrm{MPa}$ and $6.4 \%$, respectively. 

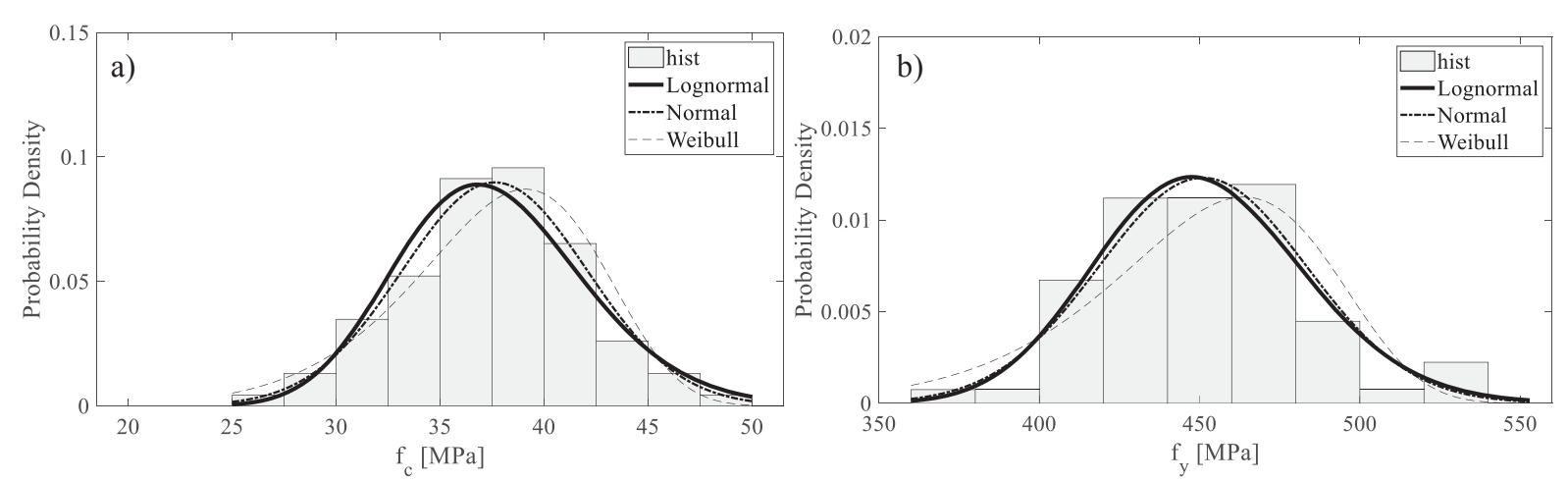

Figure 2: Probability distributions for (a) concrete compressive strength and (b) yield strength of mild steel.

A probability distribution was also fitted to experimental data on the conventional yield strength of prestressing steel $f_{p, 01}$ (i.e., the tensile stress associated with a residual strain of $0.1 \%$ ). A limited amount of data was collected by the authors and data were fitted by a lognormal distribution (Figure 3) with a mean value and $\mathrm{CoV}$ equal to $1665 \mathrm{MPa}$ and 2.5\%, respectively. These statistics agree well with different studies available in the literature (e.g., [13][13]-[15][15]).

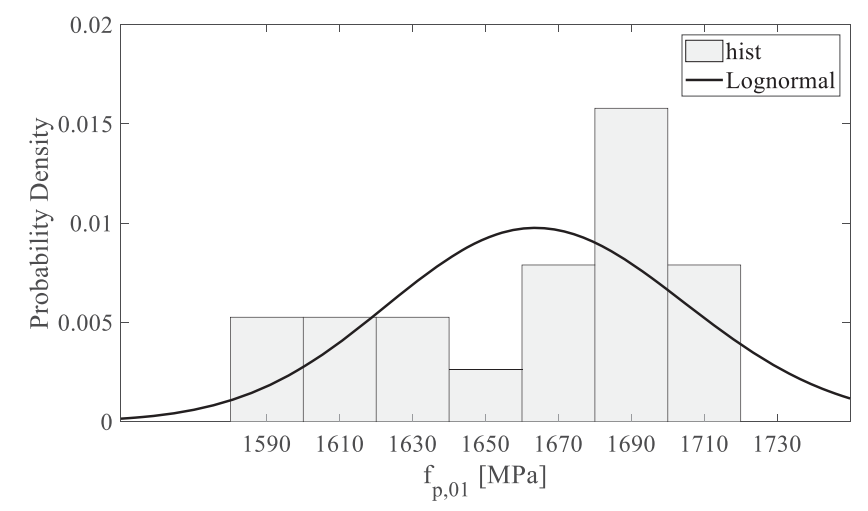

Figure 3: Probability distribution for conventional yield strength of prestressing steel.

The weight per unit volume of reinforced concrete (RC) was modelled through normal distribution with mean and $\mathrm{CoV}$ equal to $25 \mathrm{kN} / \mathrm{m}^{3}$ and $5 \%$, respectively, in order to account for the variability of permanent loads $\left(G_{1 k}\right)$. Non-structural permanent loads $\left(G_{2 k}\right)$ were modelled via a normal distribution with mean value and $\mathrm{CoV}$ equal to $2 \mathrm{kN} / \mathrm{m}^{2}$ and $10 \%$, respectively.

\subsection{Geometry}

Geometric properties were defined for simply-supported PC bridge decks built between 1960 and 1980. The cross sections of the deck and longitudinal girders are shown in Figure 4, highlighting the most relevant geometric properties considered in the analysis. 


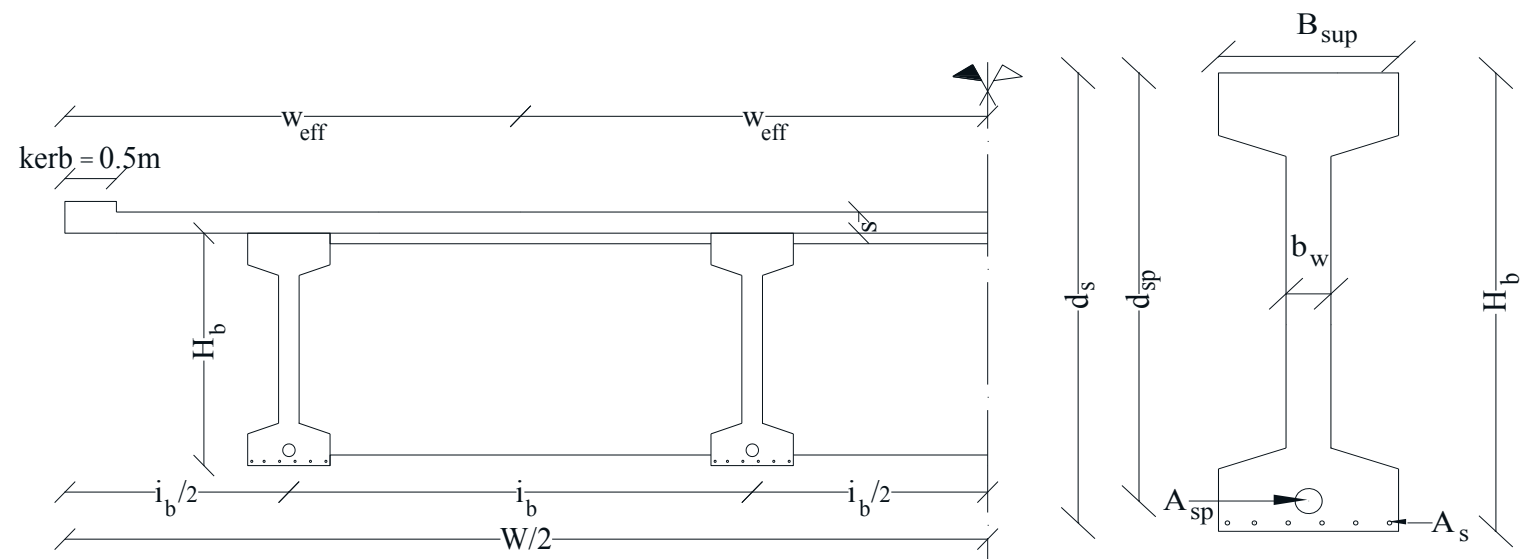

Figure 4: Cross sections of the bridge deck and longitudinal girder.

The span length $(L)$ and width $(W)$ of the deck were assumed as main independent RVs. Based on both literature [10][10] and case studies, the histogram of the bridge span length was derived. Approximately half of the existing bridges have a length between $30 \mathrm{~m}$ and $35 \mathrm{~m}$, as depicted in Figure 5. A lognormal distribution was assumed, with a mean value equal to $33.2 \mathrm{~m}$ and $\mathrm{CoV}=13.6 \%$. The distribution was truncated at $15 \mathrm{~m}$ and $45 \mathrm{~m}$ to obtain realistic values of the bridge length in subsequent probabilistic simulation.

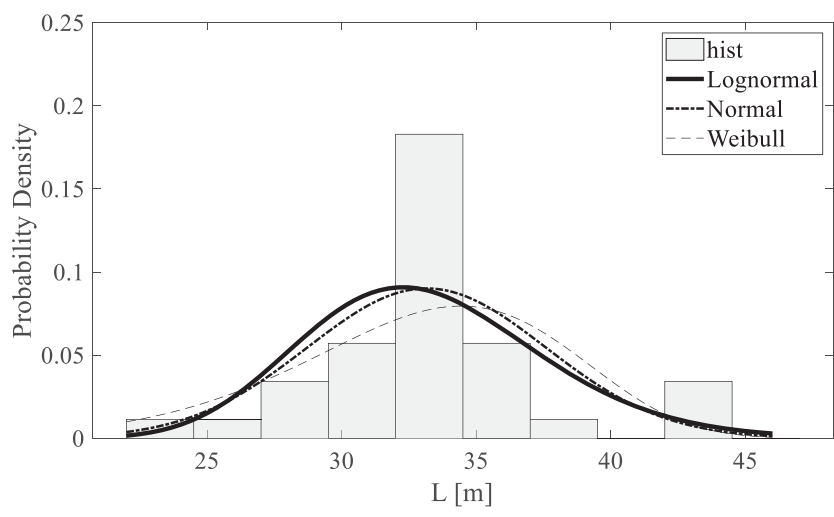

Figure 5: Probability distribution of girder span length.

Regarding the deck width $W$, a probability mass function (PMF) with three values equal to $8.5,12.25$ and $16 \mathrm{~m}$ having the same probability of occurrence was assumed. The slab thickness (denoted by $s$ ) was modelled through a uniform distribution with a mean value and $\mathrm{CoV}$ equal to $0.25 \mathrm{~m}$ and $12 \%$, respectively, in the range [0.2 $\mathrm{m}, 0.3 \mathrm{~m}]$.

The transverse reinforcement ratio $\rho_{s w}\left(A_{s w} / p\right.$, where $p$ is the distance between stirrups) and prestressing ratio of the tendons $\sigma_{s p} / f_{p, 01}$ were considered as additional independent RVs. The former was modelled through a uniform distribution between $300 \mathrm{~mm}^{2} / \mathrm{m}$ (corresponding to 8 -mm-diameter stirrups with $330 \mathrm{~mm}$ spacing as per minimum code requirement) and 1130 $\mathrm{mm}^{2} / \mathrm{m}$ (corresponding to $12-\mathrm{mm}$-diameter stirrups with $200 \mathrm{~mm}$ spacing as maximum recorded value). The prestressing ratio was modelled in two different ways: (i) uniform distribution between $40 \%$ and $60 \%$, (ii) PMF with 3 equally probable values equal to $40 \%, 50 \%$ and $60 \%$. In this study, degradation of prestressing steel was not taken into account. The residual stress levels $\sigma_{s p}$ take into account average values of relaxation loss due to concrete creep, shrinkage and relaxion of steel under tension [17][17]. 
The set of independent RVs is listed in Table 1, providing their distributions, mean $\mu$ and $\mathrm{CoV}$.

\begin{tabular}{c|c|c|c}
\hline Random variable & $\boldsymbol{\mu}$ or discrete values & CoV [\%] & Distribution \\
\hline$f_{c}[\mathrm{MPa}]$ & 34.70 & 24.40 & Lognormal \\
$f_{y}[\mathrm{MPa}]$ & 436.00 & 6.40 & Lognormal \\
$f_{p, 01}[\mathrm{MPa}]$ & 1665.00 & 2.50 & Lognormal \\
$L[\mathrm{~m}]$ & 33.20 & 13.60 & Lognormal \\
$W[\mathrm{~m}]$ & $8.50-12.25-16.00$ & - & PMF \\
$s[\mathrm{~m}]$ & 0.25 & 12.00 & Uniform \\
$\rho_{s w}\left[\mathrm{~mm}^{2} / \mathrm{m}\right]$ & 715.00 & 34.00 & Uniform \\
$\sigma_{s p} / f_{p, 01}[\%]$ & 50.00 & 12.00 & Uniform \\
$\sigma_{s p} / f_{p, 01}[\%]$ & $40.00-50.00-60.00$ & - & PMF \\
$\gamma_{c}\left[\mathrm{kN} / \mathrm{m}^{3}\right]$ & 25.00 & 5 & Normal \\
$G_{2 k}\left[\mathrm{kN} / \mathrm{m}^{2}\right]$ & 2.00 & 10 & Normal \\
\hline
\end{tabular}

Table 1: Distributions and statistics of independent random variables.

\subsection{Correlation models}

Based on case-studies, regression models were developed in order to model RVs conditioned upon independent RVs. The following dependent variables were considered:

- number of longitudinal girders, $n_{b}$;

- height of longitudinal girder, $H_{b}$;

- area of girder cross-section, $A_{b}$;

- width of girder top flange, $B_{\text {sup }}$;

- distance of equivalent total prestressing area from top of girder cross-section, $d_{s p}$;

- geometric ratio of prestressing steel $\rho_{s p}$ multiplied by $d_{s p}, \rho_{s p} \cdot d_{s p}$.

In Table 2, the regression models used in this study are listed together with their coefficient of determination $R^{2}$ and boundaries.

\begin{tabular}{c|c|c|c|c}
\hline $\mathbf{R V}$ & Regression model & $\mathbf{R}^{2}$ & $\begin{array}{c}\text { Lower } \\
\text { bound }\end{array}$ & $\begin{array}{c}\text { Upper } \\
\text { bound }\end{array}$ \\
\hline$n_{b}(W)$ & $n_{b}=0.33 \cdot W$ & 0.51 & 2 & 8 \\
$H_{b}\left(i_{b}, L\right)$ & $H_{b}=0.28 \cdot \frac{W}{n_{b}}+0.03 \cdot L$ & 0.81 & $H_{b} \geq L / 20$ & $3.2 \mathrm{~m}$ \\
$A_{b}\left(H_{b}\right)$ & $A_{b}=0.43+0.06 \cdot H_{b}^{2}$ & 0.84 & - & - \\
$B_{s u p}\left(H_{b}\right)\left(G_{l k}\right)$ & $B_{\text {sup }}=0.34 \cdot H_{b}+0.02 \cdot G_{1 k}-0.02 \cdot H_{b} \cdot G_{1 k}+0.002 \cdot G_{1 k}^{2}$ & 0.71 & - & 1.2 \\
$d_{s p}\left(H_{b}\right)$ & $d_{\mathrm{s} p}=0.98 \cdot H_{b}$ & 0.97 & - & - \\
$d_{s p} \cdot \rho_{s p}(L)$ & $\rho_{s p} \cdot d_{s p}=8.16 \cdot 10^{-5} \cdot L+1.85 \cdot 10^{-5} \cdot L^{2}$ & 0.88 & $0.007 d_{s p}$ & - \\
\hline
\end{tabular}

Table 2: Regression models

The following deterministic variables were assumed:

- concrete cover equal to $0.03 \mathrm{~m}$;

- girder web equal to $0.2 \mathrm{~m}$;

- bottom flange thickness equal to $0.3 \mathrm{~m}$;

- geometric ratio of longitudinal reinforcing mild steel equal to $0.1 \%$; 
- Young's modulus of steel equal to $200 \mathrm{GPa}$.

\section{STRUCTURAL ANALYSIS}

The first stage of structural analysis consisted in the modelling of loads on the bridge deck. Self-weight of deck components was evaluated according to $G_{l k}$, sectional area of longitudinal girders and their effective width $w_{\text {eff }}$ (which was equal to $i_{\text {beam }}$ ). Non-structural permanent loads were obtained according to $G_{2 k}$ and $w_{\text {eff. }}$.

Traffic loads were defined according to the Italian building code [8][8] and Eurocode 1 Part 2 [16][16]. The number of lanes adopted in the present study is either two or three, depending on the randomly generated geometry of the deck in order to maximize the strength demands on the edge girders (i.e., bending moment at mid-span or shear force at girder ends). The deck cross section was assumed to be rigid, according to design calculations at the time of construction and Engesser formulation [18][18]. The structural analysis procedure was implemented in MATLAB [9] in order to automatically define traffic load distributions which maximize bending moment and shear force on the edge girder.

Flexural and shear capacity models were also programmed in MATLAB to evaluate the collapse capacity of the edge girder as representative of the deck structural behaviour. The ultimate limit state (ULS) of the deck was thus defined as the attainment of either flexural or shear capacity in the edge girder.

The flexural capacity of the girder was evaluated on the basis of the following assumptions:

1. Plane cross section and perfect steel-concrete bond after flexural deformation;

2. maximum compressive concrete strain equal to $0.35 \%$;

3. uniform stress distribution and zero tensile strength of concrete;

4. mild and prestressing steel with elastic-perfectly plastic behaviour and unlimited ductility;

5. yielded steel (i.e., to be checked in all cases after neutral axis is found).

Mild steel was defined through its geometric ratio $\rho_{s}$ (e.g., $0.1 \%$ ). The flexural capacity $M_{r}$ of girder cross section was basically predicted through sectional analysis at ULS.

The shear capacity $V_{r}$ of the girder was evaluated by enveloping three different capacity models provided by current codes ([8][8], [17][17]). The first model describes the capacity of a $\mathrm{RC}$ member in cracked conditions without shear reinforcement. The second model adopted in this study applies to PC beams in uncracked conditions. The third model applies to cracked $\mathrm{RC}$ beams with internal stirrups based on a strut-and-tie resisting mechanism.

\section{COLLAPSE FRAGILITY OF CASE-STUDY BRIDGES}

Fragility analysis was based on Monte Carlo sampling of independent RVs, which allowed the random generation of 10,000 model realizations based on their probability distributions. Regression models were then used to generate statistically dependent variables, considering the model error of each regression equation. The magnitude of traffic loads was defined through an intensity measure (IM) denoted as $\alpha$ and defined as the ratio between the incremental and design first-lane tandem load, i.e. $\alpha=Q_{1} / Q_{1 d}$ with $Q_{1 d}=600 \mathrm{kN}$. Structural analysis of each set of 10,000 deck models was carried out under varying $\alpha$ from 0 to 2.5 with step of 0.1 . For each deck model, both flexural and shear capacities were computed.

The output of fragility analysis was the conditional probability of exceeding ULS given IM. The maximum demand-to-capacity ratio (DCR) between flexural DCR $\left(\mathrm{DCR}_{f}=M_{e} / M_{r}\right)$ and shear DCR $\left(\mathrm{DCR}_{s}=V_{e} / V_{r}\right)$ was assumed as limit state function. Accordingly, ULS was assumed to be attained or exceeded if DCR was equal to or greater than unity. Fragility was thus defined as follows: 


$$
\mathrm{P}[\mathrm{DCR} \geq 1 \mid \mathrm{IM}=\mathrm{im}]
$$

After that counted fragilities were computed over the whole range of IM levels, fragility curves were fitted through a lognormal distribution.

Fragility curves associated with flexural and shear failure modes were initially derived separately, considering either discrete values (Figure 6a) and uniformly distributed values (Figure 6b) of prestressing ratio. In Figure 6, the lower $x$-axis indicates the selected IM chosen (i.e., $\alpha$ ), whereas the upper $x$-axis provides the corresponding the first-lane tandem load $Q_{1}$. Figure 6 shows the higher fragility of the existing Italian bridges under study in terms of flexural failure. Indeed, the median value $\eta$ of the flexural fragility curve is lower than that of the shear fragility curve, regardless of the prestressing ratio. This means that the attainment of ULS is governed by flexural failure. As shown in Figure 6(a), shear fragility significantly reduces under increasing prestressing ratio. Table 3 outlines the median value, dispersion $\beta$ (i.e., the logarithmic standard deviation) and $R^{2}$ of each fragility curve, evidencing that the lognormal distribution fits very well the fragility points as demonstrated by $R^{2}$ very close to unity.
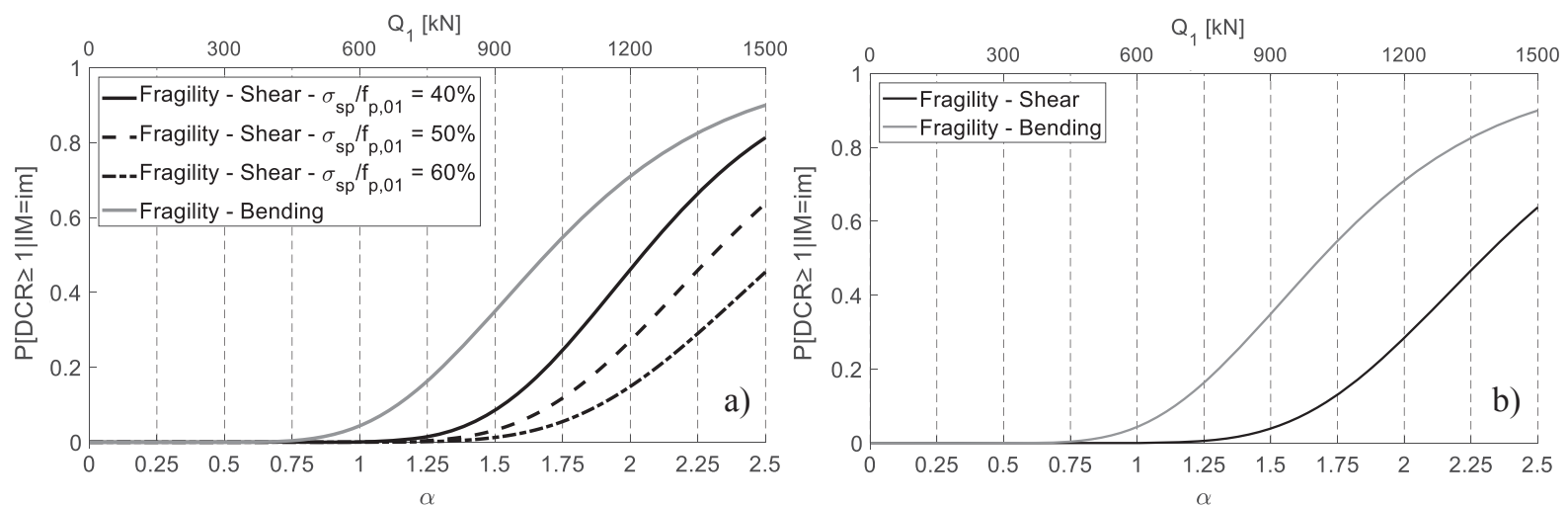

Figure 6: Fragility curves associated with flexural and shear failure modes: (a) discrete distribution of prestressing ratio; (b) uniform distribution of prestressing ratio.

\begin{tabular}{c|c|c|c}
\hline Failure mode or limit state & $\boldsymbol{\eta}$ & $\boldsymbol{\beta}$ & $\boldsymbol{R}^{\mathbf{2}}$ \\
\hline Flexural failure & 1.69 & 0.31 & \\
Shear failure $\left(\sigma_{s p} / f_{p, 01}=40 \%\right)$ & 2.04 & 0.23 & \\
Shear failure $\left(\sigma_{s p} / f_{p, 01}=50 \%\right)$ & 2.30 & 0.23 & 0.99 \\
Shear failure $\left(\sigma_{s p} / f_{p, 01}=60 \%\right)$ & 2.57 & 0.24 & \\
Shear failure $\left(\sigma_{s p} / f_{p, 01}\right.$ uniformly distributed $)$ & 2.30 & 0.24 & \\
ULS & 1.68 & 0.30 & 0.99 \\
\hline
\end{tabular}

Table 3: Fragility parameters corresponding to flexural failure, shear failure, and ULS.

Figure 7 shows the fragility curve of the case-study bridges for the limit state of collapse, which is almost totally overlapped to that associated with flexural failure mode. However, the median value and dispersion are slightly different from those related to the flexural fragility curve because of a very rare occurrence of shear failure in some model realizations. Table 3 shows that the selected bridges have a median collapse traffic load equal to 1.68 times the design load, with a dispersion $\beta=0.30$. It is also found that the conditional probability of collapse under design traffic load (corresponding to $\alpha=1$ ) is $4.4 \cdot 10^{-2}$. Further studies are needed to assess the unconditional failure probability of collapse, namely, the failure probability derived as a convolution of fragility and traffic load hazard. 


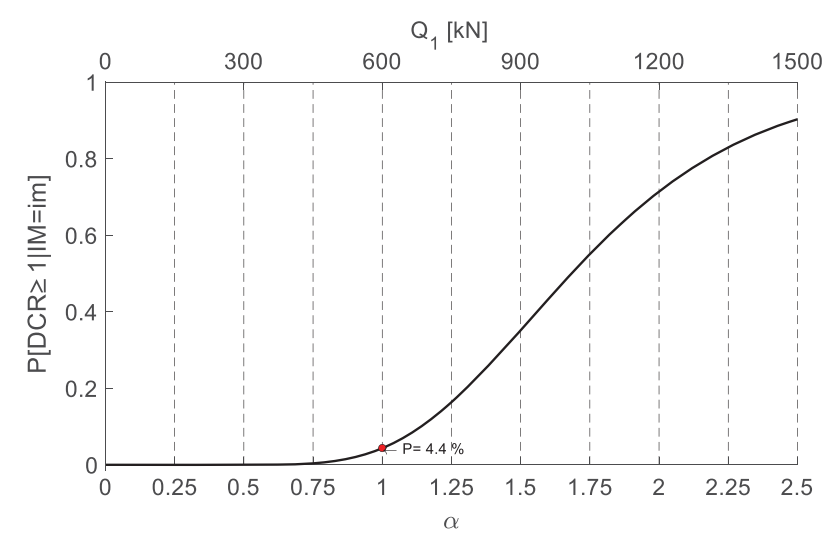

Figure 7: Collapse fragility curve of case-study bridges.

\section{CONCLUSIONS}

This study aimed at evaluating the fragility of existing Italian, simply supported, beamtype, prestressed concrete bridges. A fragility analysis procedure was implemented in MATLAB software to generate a set of 10,000 random samples of bridge deck models and carry out their structural performance assessment. The procedure starts considering a set of variables, including independent variables modelled through probability distributions, dependent variables evaluated through regression models, and deterministic variables. Assuming code-conforming traffic-load models, each bridge model was randomly generated according to Monte Carlo sampling technique and was analysed under incremental loading to detect the attainment of both flexural and shear failure modes. In this regard, three alternative capacity models were considered to predict shear resistance of edge longitudinal girders.

The fragility of Italian existing bridges was calculated by assuming the scale factor $\alpha$ of traffic loads as intensity measure IM, which was gradually incremented from 0 to 2.5. The demand-to-capacity ratio DCR was considered as limit state function, hence identifying the occurrence of flexure or shear failure modes. These latter were first probabilistically assessed separately and then considered altogether to develop the collapse fragility curve of the selected bridges. The large number of random samples allowed the estimation of collapse fragility according to a frequentist approach.

Analysis results show that the case-study bridges are significantly more vulnerable to flexural failure than to its shear counterpart. In addition, shear fragility reduces under increasing prestressing ratio.

On the basis of these outcomes, it can be inferred that flexural behaviour has a remarkable effect on the vulnerability of the considered class of existing bridges. These preliminary results suggest a prioritization scheme for structural retrofitting of existing bridges against traffic loads.

\section{ACKNOWLEDGEMENTS}

This study was supported by GRISIS research project (Gestione dei Rischi e Sicurezza delle Infrastrutture a Scala regionale, Cup: B63D18000280007) funded by Regione Campania. 


\section{REFERENCES}

[1] C. Nuti, B. Briseghella, T. Iori, I. Vanzi, Alcune riflessioni sul Viadotto Polcevera, dal progetto ai giorni nostri (Accessed online on March 8th, 2021, at https://www.enea.it/it/seguici/events/save-the-date-monitoraggio-e-valutazione-diponti-e-viadotti-1/NutiCEnea14febb2014.pdf), 2019 (in Italian).

[2] E. Cosenza, D. Losanno, A focus on the new Italian guidelines for safety assessment of existing bridges. In: Proceedings of Capacity Assessment of Corroded Reinforced Concrete Structures Conference (CACRCS 2021), Online, November-December 30-3, 2021.

[3] Italian High Council of Public Works, Linee Guida per la classificazione e gestione del rischio, la valutazione della sicurezza ed il monitoraggio dei ponti esistenti. Italy, 2020 (in Italian).

[4] Italian Ministry of Infrastructures and Transportation, Decreto ministeriale numero 578 del 17/12/2020. https://www.mit.gov.it/normativa/decreto-ministeriale-numero-578-del17/12/2020, Italy, 2020 (in Italian).

[5] W. Cook, P.J. Barr, M.W. Halling, Bridge failure rate. Journal of Performance of Constructed Facilities, 29, 2013.

[6] L. Deng, W. Wang, Y. Yu, State-of-the-art review on the causes and mechanisms of bridge collapse. Journal of Performance of Constructed Facilities, 30, 2016.

[7] K. Wardhana, F.C. Hadipriono, Analysis of recent bridge failures in the United States. Journal of Performance of Constructed Facilities, 17, 144-150, 2003.

[8] Italian Ministry of Infrastructures and Transportation, Aggiornamento delle «Norme tecniche per le costruzioni». Supplemento ordinario n. 8 alla Gazzetta ufficiale del 202-2018, Italy, 2018 (in Italian).

[9] MATLAB, 2018. 9.7.0.1190202 (R2019b), Natick, Massachusetts: The MathWorks Inc.

[10] B. Borzi, P. Ceresa, P. Franchin, F. Noto, G.M. Calvi, P.E. Pinto, Seismic Vulnerability of the Italian Roadway Bridge Stock. Earthquake Spectra, 31, 2137-2161, 2015.

[11] P.E. Pinto, P. Franchin, Issues in the Upgrade of Italian Highway Structures. Journal of Earthquake Engineering, 14, 1221-1252, 2010.

[12] P. Baratono, A. Cosentino, S. Puggelli, E. Renzi, W. Salvatore. Le nuove line guida per la classificazione e gestione del rischio, la valutazione della sicurezza ed il monitoraggio dei ponti esistenti approvate dal Consup. Ingenio, 2020 (in Italian).

[13] F.D. Wiśniewski , P.J.S. Cruz , A. Abel, R. Henriques, R.A.D. Simões, Probabilistic models for mechanical properties of concrete, reinforcing steel and pre-stressing steel. Structure and Infrastructure Engineering, 8(2), 111-123, 2012.

[14] L. Jacinto, M. Pipa, L.A.C. Neves, L. Oliveira Santos, Probabilistic models for mechanical properties of prestressing strands. Construction and Building Materials, 36, 84-89, 2012.

[15] A. Naaman, A. Siriaksorn, Reliability of partially prestressed beams at serviceability limit states. PCI Journal, 27, 66-85, 1982.

[16] CEN, EN1991-2. Eurocode 1: Actions on structures - Part 2: Traffic loads on bridges. Committee Européen de Normalisation, Brussels, 2003. 
[17] CEN, EN1992-1-1. Eurocode 2: Design of concrete structures - Part 1-1: General rules and rules for buildings. Committee Européen de Normalisation, Brussels, 2004.

[18] C. Cestelli Guidi, Cemento armato precompresso. 7th edition, Hoepli, Milan (in Italian). 